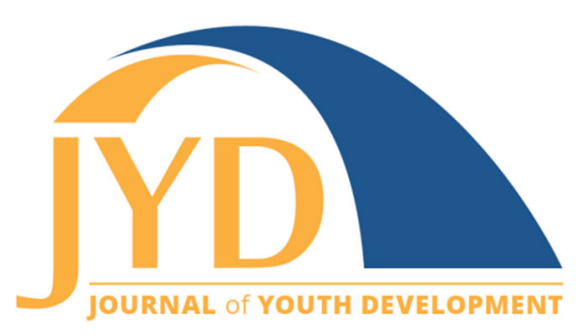

http://jyd.pitt.edu/ | Vol. 15 Issue 5 DOI 10.5195/jyd.2020.797 | ISSN 2325-4017 (online)

\title{
Mindful Learning Experiences Through Structured Reflections During a Youth Travel-Abroad Program
}

\author{
Gary D. Ellis \\ Texas A\&M University and Texas A\&M AgriLife Research \\ gellis@tamu.edu
}

Andrew Lacanienta

California Polytechnic State University

alacanie@calpoly.edu

William F. Zanolini

Texas A\&M AgriLife Extension Service

wfzanolini@ag.tamu.edu

Darlene Locke

Texas A\&M Agrilife Extension Service

dlocke@ag.tamu.edu

Jingxian Jiang

Texas A\&M University

kellyjiang@exchange.tamu.edu

\begin{abstract}
Mindfulness is an actively engaged state of mind when an individual is attuned to their surrounding multisensory elements. Mindful learning experiences during youth programs may enhance learning and the overall quality of experiences. We developed, executed, and evaluated an end-of-day structured mindfulness experience during a 4-H travel camp. In this paper we summarize the program and its outcomes and share details we believe will assist other youth professionals who may want to build structured mindfulness experiences into their own programs. Through the 4-H Global Travelers program, 20 youth participated in a 7-day travel camp in Argentina. At the end of each day campers gathered to engage in a 20-minute guided reflection of that day's activities. We projected photographs taken throughout the day to facilitate recall of and reflection on their experiences that day. Campers' responses to questions about the quality of their experience immediately following each of the mindful reflection sessions showed that sessions were highly absorbing, mindful learning experiences.
\end{abstract}

Key words: absorption, experience design, mindfulness, structured experiences

(cc) EY New articles in this journal are licensed under a Creative Commons Attribution 4.0 License. This journal is published by the University Library System, University of Pittsburgh and is cosponsored by the University of Pittsburgh Press. The Journal of Youth Development is the official peer-reviewed publication of the National Association of Extension 4-H Youth Development Professionals and the National AfterSchool Association. 


\section{Mindfulness and Absorption}

The most prominent theories on human development share a common theme: "Young people have tremendous potential for growth. . . . They have natural dispositions to learn and grow from challenging activities" (Larson \& Walker, 2018, p. 156). A major function of youth programs, then, is to structure challenging and rewarding experiences providing opportunity for learning and growth. Youth programs such as residential camps, after-school programs, studyabroad programs, and travel camps provide a wealth of daily challenges, each carrying unique learning opportunities. Learning outcomes from these diverse activities range from developing specific activity skills to learning complex abilities essential to "thriving" (i.e., progressing toward fulfilling one's full potential; Caldwell \& Witt, 2018; Bundick et al., 2010).

Yet not all challenges encountered during youth programs are equal in learning potential. The manner in which a given challenge is structured can have a pivotal impact on the depth and significance of what is learned. During her career spanning over 4 decades, Harvard psychologist Ellen Langer demonstrated the potency of "mindfulness" and "mindful" learning strategies. "Mindfulness," Langer explains, "is a flexible state of mind in which we are actively engaged in the present, noticing new things and sensitive to context" (Langer, 2000, p. 220). Mindful teaching strategies, then, are those that invite active exploration of the object of learning, regardless of whether that object is a mathematical equation or the ecosystem of which a particular delicate plant is a part. A mindful approach to teaching about that plant would include comments encouraging learners to notice its many colors, its aroma, its shape, the composition of the soil in which it is growing, and the plant's position among other nearby natural and built features. Learners would be invited to explore the plant through questions such as: "Why might this plant have grown in this particular location?", "What are some of the different colors can you detect on the plant?", and "What function might those colors serve?" In contrast, a "mindless" approach involves communication limited to precise instructions and factual information. Learners exposed to mindless instruction might be told the name of the plant and why it thrives in particular conditions of soil, shade, and water. Mindful learning can be very powerful, particularly if learners are consistently exposed to mindful teaching strategies. A learned disposition toward mindfulness yields benefits that are "vast and often profound. . . . Mindfulness results in an increase in competence; a decrease in accidents; an increase in memory, creativity, and positive affect; a decrease in stress; and an increase in health and longevity" (Langer, 2000, p. 220). We developed, executed, and evaluated an end-of-day structured mindfulness experience during a $4-\mathrm{H}$ travel camp. The purpose of this paper is to describe the program and, based on our experience, provide suggestions youth professionals might use to implement a similar program. 


\section{Mindfulness and Absorption}

\section{Significance: Intentionally Designing Quality Learning Experiences}

Virtually all youth programs aim to teach, educate, or focus on benefits, outcomes, or transformations (Allen et al., 1998; Pine \& Gilmore, 2011). Providers of youth programs commit substantial resources to teaching youth and helping them learn, grow, and develop into thriving adults (Witt \& Caldwell, 2018). Mindfulness reflection experiences can be an impactful addition to many of these programs. Mindfulness learning experiences increase understanding, facilitate retention of knowledge, and capture and hold attention in educational environments (e.g., Langer, 2000; Ramsburg \& Youmans, 2014).

In addition to the definition advanced by Langer (2000) presented earlier in this paper, mindfulness has been defined as "a mental discipline aimed at training attention" (Hassed \& Chambers, 2014, p. 6) and "the awareness that emerges through paying attention on purpose, in the present moment, and non-judgmentally to the unfolding experience moment by moment" (Kabat-Zinn, 2003, p. 145). These definitions share common elements. When people are mindful, their attention is focused fully on the task or setting immediately at hand. They are not thinking about the past, nor are they engaged in automatic, mindless actions (Langer, 2014b). "To be mindful while eating," Hassed and Chambers (2014) explain, "is to taste the food. To be mindful while taking a shower is to feel the water and its warmth. To be mindful while walking is to feel the body moving and to engage with the environment. To be mindful while learning is to pay attention to the teacher. To be mindful while teaching is to pay attention to the students" (p. 9).

Mindful learning experiences occur when students and teachers focus their attention fully on the present. Learners' immediate experiences are not tempered by such matters as regret or reflection on the past or ambition or worry about the future. Learners' actions are deliberate and intentional rather than occurring automatically and mindlessly. Although rote memorization of facts can also occupy learners' full attention, rote memorization is not mindful learning. Rather, mindful learning experiences have three distinctive characteristics: (a) continuous discovery of new categories of features, functions, and contrasts of the objects that are the focus of attention; (b) a spirit of openness to new information; and (c) an implicit awareness that more than one perspective can be taken on the object that is the focus of attention (Langer, 2016).

Experimental research confirms that mindful learning experiences increase knowledge retention. Ramsburg and Youmans (2014) conducted three randomized experiments to evaluate the effect of mindfulness experiences on university students' retention of materials taught through 


\section{Mindfulness and Absorption}

lectures. In each of the first two experiments, groups of randomly selected students engaged in a brief mindfulness meditation exercise while a second group simply closed their eyes and rested. In both experiments, the groups that engaged in the mindful meditation exercise scored significantly higher on a post-lecture quiz than the group that rested. The third experiment yielded results consistent with the first two, but also indicated that the mindfulness meditation effect was not dependent on the presentation style (live vs. recorded lecture) or topic (related or unrelated to mindfulness). The authors speculated that mindfulness increased retention by enhancing students' "self-regulatory functioning, specifically their ability to delay gratification or avoid impulsive behaviors" (p. 437). In other words, helping students focus on the lecture through mindful meditation may have minimized the energy cost of redirecting attention to and from content unrelated to the lectures.

Mindfulness techniques have also been shown to enhance moods and promote relaxation (Fiocco \& Mallya, 2015; Gallant, 2016; Ricarte et al., 2015). Arias and colleagues (2006) conducted a meta-analysis of 82 studies in which mindfulness meditation techniques had been included as part of treatment of individuals with medical and psychological problems. Their findings supported the potential efficacy of mindfulness in mood elevation and of its associated relaxation as key components of medical treatment for patients with particular illnesses. In research with youth, Ricarte et al. (2015) conducted a field experiment in which a 6-week mindfulness intervention was implemented in a rural school. Students who participated in the program showed improved moods, better concentration, and enhanced verbal memory. The program did not, however, increase focused attention or working memory.

Mindfulness techniques may also play an important role in determining the quality of experiences of youth during structured activities in out-of-school time programs. Such programs must be engaging, immersive, or absorbing in addition to providing opportunities for learning, growth, and development (Ellis et al., 2018). Activities that are not experienced by youth as rewarding and worth their time investment will not be pursued, leading to attrition and loss of opportunity for learning and development. Given the extensive body of theory, research, and application exuding the potential immediate and long-term benefits of mindfulness (e.g., Burk, 2014; Hyland, 2011; Le et al., 2014), this investigation was directed at developing, executing, and evaluating an end-of-the day structured mindfulness experience to facilitate learning from daily activities in a 4-H study-abroad travel camp.

Our approach was descriptive, primarily directed at evaluating the extent to which participants experienced the activity as absorbing. Absorption is a subjective experience of heightened 


\section{Mindfulness and Absorption}

attention, motivation, and emotion characterized by relaxation, pleasure, and the absence of demand for behavioral action or active thinking (Ellis, Freeman, Jamal, \& Jiang, 2019; Pine \& Gilmore, 2011). Mindful reflection, meditation and relaxation are examples of an absorbing experience. Our study thus addressed the question of whether end-of-day structured mindfulness experiences were absorbing and added value to youths' overall travel camp experience.

\section{Method}

\section{Participants}

During a structured reflections program we collected 108 observations of quality of experience from 20 youth ambassadors in the Texas 4-H Livestock Ambassador Program. Youth ambassadors engaged in a 14-day learning experience in Argentina. They were $70 \%$ female, and their ages ranged from 16 to 19 . Daily activities included tours to ranches, farms, wineries, markets, and other agriculture-based sites.

\section{The Texas 4-H Livestock Ambassador Program}

The Texas 4-H Livestock Ambassador program provides high school aged 4-H members the opportunity to develop and practice advanced leadership skills related to mentoring other youth, and to become advocates for animal agriculture. Over the years, the program has expanded to include state, national and international leadership experiences. The youth ambassadors advance through the program in three phases: (a) Texas 4-H Livestock and Equine Ambassador short courses, (b) Texas 4-H Livestock and Equine Ambassador Advocacy Academy, and (c) Texas 4-H Livestock and Equine Ambassador domestic and international study experiences.

The short courses (Phase 1) are held at four different universities in Texas. Ambassadors study in a rigorous program of university-level animal science classes. They learn to be leaders in junior livestock and equine programs, become prepared for university learning experiences, learn to serve in advocacy roles, and develop awareness of industry-related careers while mentoring other youth. Phase 2 is the Ambassador Advocacy Academy: Youth travel to the state capital and participate in hands-on learning about the political process. Their curriculum includes media training, agricultural law and lobby, ethics of agriculture technology, agricultural policy, consumer communications, and collegiate internship opportunities.

We implemented our mindful reflections program during Phase 3 of the program: Equine Ambassador domestic and international study experiences. Participants engage in a 10-day 


\section{Mindfulness and Absorption}

agricultural study experiences at an international destination. They are immersed in agricultural learning through impactful visits to family farms, ranches, and other agricultural enterprises. They have the opportunity to interact with agriculture policy makers of the host country, and they gain a better understanding of regulations, growing practices, and similarities and differences between Texas agriculture versus the country visited. Program leaders immerse Ambassadors in cultures of the country visited, enlightening and expanding their views of the world. Each study experience offered has customized sessions to target specific learning outcomes. For the experience in Argentina, 4-H specialists targeted low input agriculture, international trade, and South American culture.

\section{Procedures}

At the end of each of 7 days during the study-abroad experience, the 20 youth participated in a structured mindfulness experience. The activity was a guided, mindful reflection on venues, attractions, and locations visited that day. These mindfulness activities occurred in hotel rooms, empty sections of restaurants, or other public spaces. Each session began with a brief period of silence, where participants were asked to take deep breaths, relax, "be where their feet are," and reflect on their experiences during that day. Next, the 4- $\mathrm{H}$ professional explained that he would be projecting photographs from the day's experiences on a screen for everyone to view. The photographs for the slideshow were assorted images adult leaders of the experience took during that day's experiences. The 4-H professional encouraged participants to focus their attention on the photographs and notice new and exciting details. The slideshow was then projected to a wall or make-shift screen. Consistent with mindfulness learning practice, participants were guided in viewing the photos to reflect mindfully on the thoughts and experiences of the day. Each photograph viewing session lasted approximately 15 minutes. Table 1 provides five specific suggestions for facilitating reflections sessions in similar youth programs. These suggestions are derived from the 4- $\mathrm{H}$ specialist's experience in conducting the reflections sessions.

\section{Measurement of Quality of Experience}

After viewing the slideshow, the youth Ambassadors completed a brief electronic questionnaire, using their personal devices. The questionnaire measured five indicators of experience quality: absorption, deep-structured experience prevalence (DSEp), perceived value of time spent (PV), delight, and the proclivity to promote the activity. 


\section{Mindfulness and Absorption}

\section{Absorption}

Mindfulness is the theoretical foundation for the subjective experience of absorption (Ellis, Freeman, Jamal, \& Jiang, 2019). Absorption is characterized by high levels of relaxation, pleasure, absence of a flow of demands for behavioral or mental action in response to stimuli, and mindfulness (Ellis, Freeman, Jamal, \& Jiang, 2019; Langer, 2000; Pine \& Gilmore, 2011). Our questionnaire prompt read, "Approximately what percent of the time during the reflection experience did you feel [each of the following]." A "slider scale" from 0 to 100 percent was included for each of the following: pleasure, relaxation, focused on the present moment, free of stress, and absorbed. Responses were summed to form a measure of absorption. The scale produced an alpha reliability of .82 .

\section{Deep-Structured Experience (DSE)}

Participants were presented with the definition of DSE: "Deep experience is defined as effortless concentration so deep that you lose: (a) your sense of time, (b) your thoughts about yourself, and (c) your thoughts about your problems. You wanted very much to keep doing this activity." Following that definition, DSE prevalence was assessed by asking, "Approximately what percent of the time did you feel that you were in a state of deep experience?" Responses were provided on a slider scale from 0 to 100 percent (Ellis, Freeman, Jiang, \& Lacanienta, 2019).

\section{Perceived Value of Time Spent}

PV was measured using a five-item Likert scale (Ellis et al., 2016). Participants were asked to indicate the extent to which they agreed with statements by assigning a value from 1 (disagree) to 7 (agree) to each statement. An example item from this portion of the survey is, "This activity was an excellent use of my time." High scores indicated that the respondents considered their choice to participate in the structured experience to be preferable to other options. Scores were calculated by summing across the items. The alpha reliability of the PV scale was .86 .

\section{Delight}

Oliver (2010) defined delight as "an extreme expression of affect" and "a high-arousal manifestation of satisfaction" (p. 22). Consistent with previous research (Ellis et al., 2018; Lacanienta et al., 2018), delight consisted of a single-item measure with a 5-point "slider scale" response format. Anchor points for that scale ranged from "delight" to "disgust." Delight scores were calculated by assigning a value from 1 (disgust) to 5 (delight) to each response and summing across items. 
Table 1. Guidelines for Structuring a Guided Reflections Program for Youth at Different Phases of a Reflection Session

\begin{tabular}{|c|c|}
\hline Phase & Guidelines \\
\hline \multirow{3}{*}{ 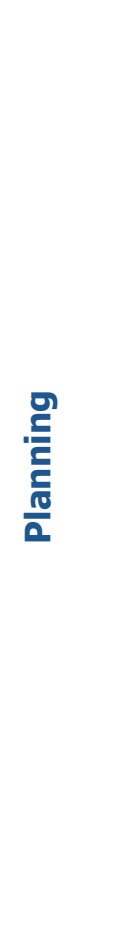 } & $\begin{array}{l}\text { Use "less is more" as a foundation for planning. Mindful absorption activities should be } \\
\text { positive, relaxing, and need not require lengthy investment of physical energy or mental } \\
\text { attention. Promote focused attention, relaxation, and to invite discovery of new features and } \\
\text { unique categories of the photographs. Allowing } 20 \text { minutes from set-up to take-down is } \\
\text { sufficient time for an impactful mindfulness experience. }\end{array}$ \\
\hline & $\begin{array}{l}\text { Choose photographs strategically. We found that pictures of places and things provide } \\
\text { great context, and pictures of people in those places enhance the reflection experience. We } \\
\text { recommend compiling photographs participants take each day as well as photographs taken } \\
\text { by adult leaders. }\end{array}$ \\
\hline & $\begin{array}{l}\text { Secure a quiet, comfortable and private location to eliminate distractions. We } \\
\text { found that quality reflection experiences are very possible even in unlikely circumstances. We } \\
\text { sometimes used bed sheets as projection screens, and we organized sessions in relatively } \\
\text { quiet corners of restaurants. Choose spaces that are not too crowded, too hot, too cold, too } \\
\text { noisy, and free from unpleasant aromas. Think about comfortable seating (e.g., chairs, } \\
\text { pillows on the floor, yoga mats, grass). }\end{array}$ \\
\hline \multirow{2}{*}{ 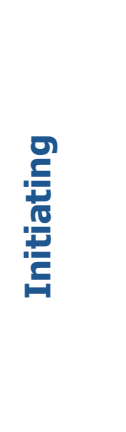 } & $\begin{array}{l}\text { Mentally prepare youth for focusing on the present. In our case, this meant focusing } \\
\text { on the slides. A very effective phrase we used consistently was "be where your feet are." } \\
\text { Youth ambassadors quickly realized that this phrase reminded them to focus on the present } \\
\text { instead of thinking about the past, the future, or matters unrelated to the reflection activity. }\end{array}$ \\
\hline & $\begin{array}{l}\text { Encourage relaxation. Reflections are most effective when students are rested and } \\
\text { content. Invite participants to close their eyes and focus on their breathing for a minute or so } \\
\text { before the focus on the slideshow images begins. }\end{array}$ \\
\hline \multirow{2}{*}{ 宔 } & $\begin{array}{l}\text { Limit the number of things you ask youth to do during the session. Mindful reflection } \\
\text { should be a time for participants to intentionally observe, classify, discover, and reflect-not } \\
\text { much more. }\end{array}$ \\
\hline & $\begin{array}{l}\text { Encourage focused observation and creative interpretation. You might point out, for } \\
\text { example, that any given photograph may, suggest something about agriculture, friendships, } \\
\text { culture, poverty, and prosperity. }\end{array}$ \\
\hline 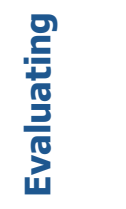 & $\begin{array}{l}\text { Orient youth to questionnaires in advance. If your reflection program includes an } \\
\text { evaluation component, familiarize participants with the questionnaire in advance. Let them fill } \\
\text { in responses and talk about any concepts that may be confusing or ambiguous in meaning. }\end{array}$ \\
\hline
\end{tabular}




\section{Mindfulness and Absorption}

\section{Proclivity to Recommend}

A single-item scale "net promoter score" (Reichheld, 2003) was used to measure the proclivity of participants to recommend the mindfulness activity to others. Reichheld argued that using a single question to replace the "complex black box of the typical customer satisfaction survey" can ". . . put consumer survey results to use and focus employees on the task of stimulating growth" (p. 3 ). The approach used a 10-point scale. Respondents were asked to indicate the likelihood of promoting the product or service (in the case of this program, the reflection experience) to their friends, family, or colleagues. The scale anchors were 10 (extremely likely) and 0 (not at all likely); neutra/ was printed at the midpoint of the scale.

\section{Data Analysis}

Analysis consisted of two phases. We were primarily interested in the quality of experience of participants. Based on Langer's (2000) assertion that mindful learning yields motivation and pleasing states of emotion, we anticipated negatively skewed (scores largely clustered toward the highest end of the scale) and leptokurtic (i.e., more "peaked" than the normal curve) distributions with very high measures of central tendency and limited variation. Secondarily, we sought to confirm the validity of our measures. TSE propositions assert that all of the indicators of experience quality should have significant, positive, and moderate-to-strong correlations. Relations among the measures were estimated using linear mixed modeling procedures.

\section{Results}

Distributions of the four variables were consistent with predictions (Figures 1-5). All distributions showed substantial negative skewness, ranging from -1.33 (absorption) to -3.26 (perceived value). They were also leptokurtic, with values ranging from 1.02 (absorption) to 10.91 (perceived value). The means and medians, respectively, expressed as percentages of the highest possible scores were as follows: absorption, $88 \%$ and $96 \%$; perceived value, $96 \%$ and $100 \%$; DSEp, $90 \%$ and $96 \%$; delight, $97 \%$ and $100 \%$, and proclivity to recommend $95 \%$ and $100 \%$. Coefficients of variation (standard deviation per unit of mean) reflected substantial consistency in ratings. Participants found the mindful reflection activity to be highly absorbing. Bivariate standardized coefficients among the measures were all significant, positive, and moderate-to-strong in association. Bivariate correlations between absorption and DSEp, PV, delight, and proclivity to recommend were all significant at $p<.01$. Thus, results indicate validity; it is justifiable to make inferences about the quality of participants' experiences based on the scores on our measurement tools. 
Journal of Youth Development | http://jyd.pitt.edu/ | Vol. 15 Issue 5 DOI 10.5195/jyd.2020.797

Mindfulness and Absorption

Figure 1. Distribution of Absorption Scores

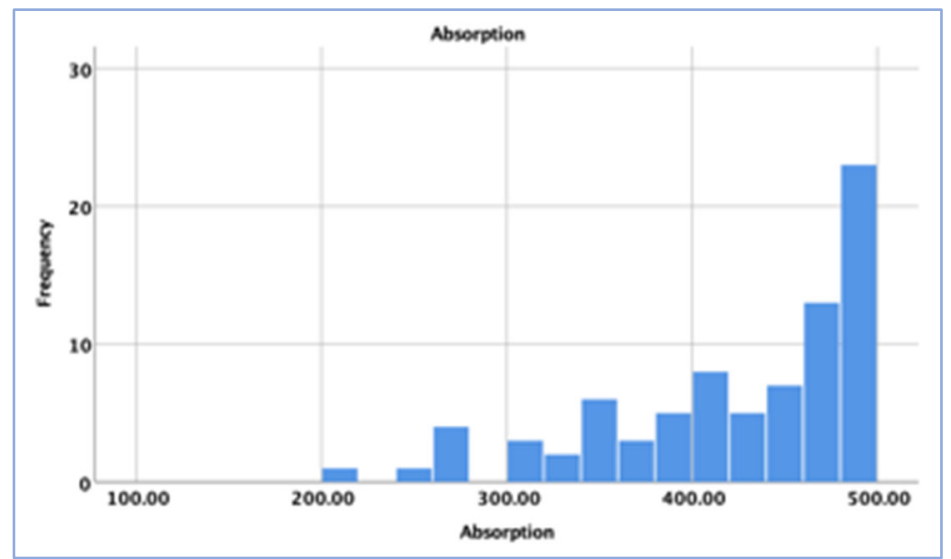

Figure 2. Distribution of Deep-Structured Experience Scores

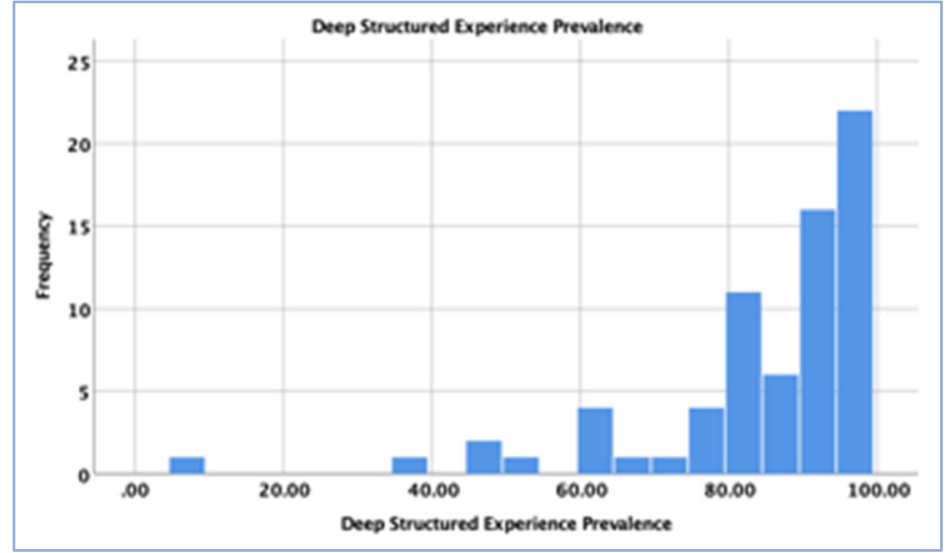

Figure 3. Distribution of Perceived Value Scores

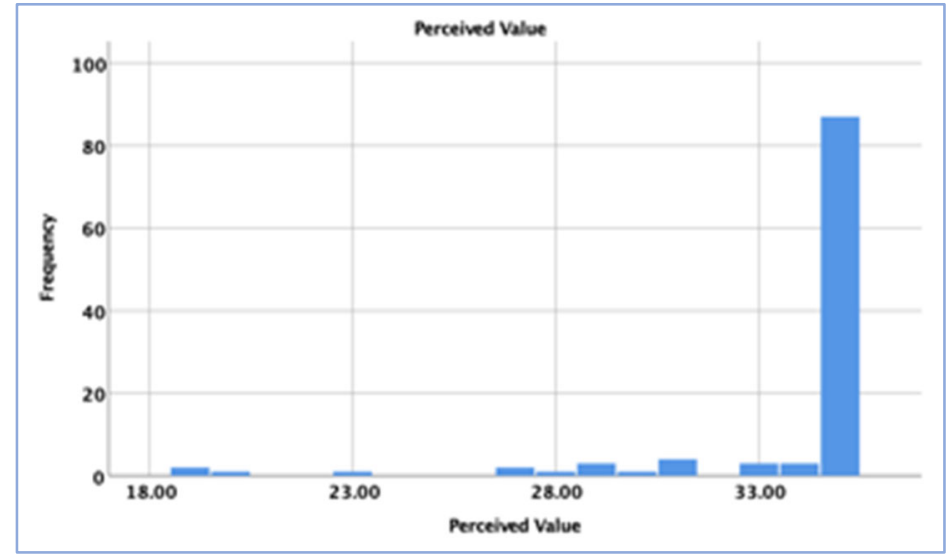


Figure 4. Distribution of Delight Scores

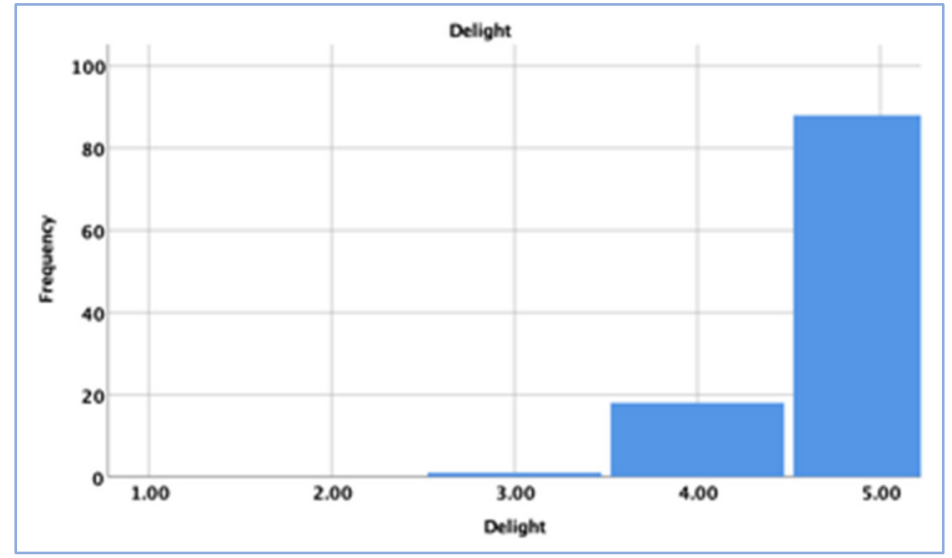

Figure 5. Distribution of Proclivity to Recommend Scores

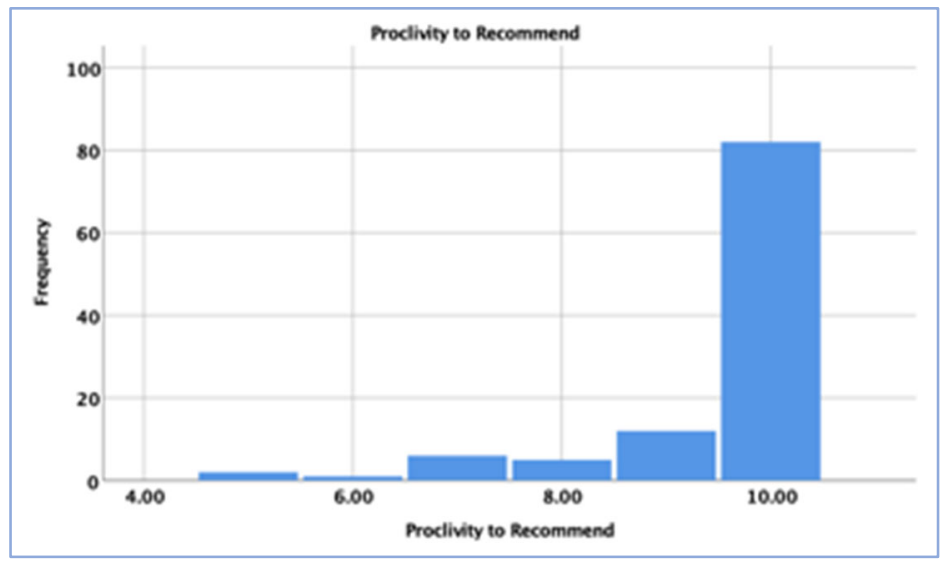

\section{Discussion}

We sought to develop, execute, and evaluate an end-of-day structured-mindfulness experience to facilitate mindful reflection on daily activities in a 4-H study-abroad experience, and to share recommendations for designing reflections experiences in similar youth programs. Findings suggest that we accomplished our goal of crafting an absorbing, mindful learning activity suitable for structured, end-of-day reflection experiences during youth study-abroad programs. The structured mindfulness experiences showed substantial negative skewness across all variables (indicating high levels of absorption, delight, perceived value, deep experience, and proclivity to recommend), high means and medians, and high levels of consistency across variables. These results provide evidence that structured mindfulness experiences are highly absorbing. Mindful learning is related to positive, absorbing experiences. Time spent in mindful reflection was related to high perceptions of value and considered worthy of being recommended to friends. 


\section{Mindfulness and Absorption}

It is very important to note, however, that the project has significant limitations if critiqued through the lens of standard for quality behavioral science. The design does not yield data for comparison with alternative approaches to structuring the reflections program, nor does it protect against key threats to internal validity. The number of participants was small, and it would be quite a "stretch" to try to characterize the youth ambassadors in this program as a random sample selected from a well-defined population of youth. Thus, the research design yields no greater confidence in cause and effect than a survey or other form of correlational, observational, or descriptive research. Laboratory and field experiments are needed to understand causes and effects scientifically. Such research should explore the learning value of reflection experiences, confirm best practices in structuring mindful reflection sessions for youth who participate in travel and camp experiences, and confirm the range of applicability to camps and other youth programming settings. Our project follows contemporary evaluation practice, though, and results are consistent with expectations we have about the extent to which mindful reflection sessions can be absorbing, high quality experiences. These results may thus serve as a premise as we build an inductive argument about mindful reflection sessions in select youth programs: the mindful reflection session we included in our education program was highly absorbing. Perhaps similar procedures will yield similar results in similar circumstances. Readers may find the suggestions we provide helpful in designing their own mindful reflection sessions to increase the impact of their own programs.

\section{Resources}

A number of web resources are available to educators, researchers and youth-service-industry professionals interested in building mindfulness experiences into their programs. A search of the web will reveal mindfulness centers at several universities, including University of Massachusetts, University of California at San Diego, University of California Los Angeles, Brown University, Stanford University, and others. The American Mindfulness Research Association also has a very helpful website. That association, founded in 2013, addresses the mission of supporting empirical and conceptual efforts to establish an evidence base for mindfulness, promote best practices, and facilitate discovery of new knowledge about mindfulness. A scientific journal, Mindfulness, publishes research and best practices papers on mindfulness. Numerous books have been published on mindfulness; Langer's books on mindfulness (e.g., 2014a, 2014b, 2016) are particularly well-written and helpful. For educators, we also recommend Hassed and Chambers' (2014) book, Mindful Learning. 


\section{References}

Allen, L. R., Stevens, B., Hurtes, K., \& Harwell, R. (1998). Benefits-based programming of recreation services training manual. National Recreation and Park Association.

Arias, A. J., Steinberg, K., Banga, A., \& Trestman, R. L. (2006). Systematic review of the efficacy of meditation techniques as treatments for medical illness. Journal of Alternative and Complementary Medicine, 12, 817-832. https://doi.org/10.1089/acm.2006.12.817

Bundick, M. J., Yeager, D. S., King, P. E., \& Damon, W. (2010). Thriving across the life span. In W. F. Overton \& R. M. Lerner (Eds.), The handbook of life-span development, Vol 1. Cognition, biology, and methods (pp. 882-923). John Wiley \& Sons. https://doi.org/10.1002/9780470880166.hlsd001024

Burk, D. S. (2014). Mindfulness. Penguin Group.

Caldwell, L. \& Witt, P. (2018). Ten principles of youth development. In P. Witt \& L. Caldwell (Eds.), Youth development: Principles and practices in out-of-school time settings (pp.1-25). Sagamore Venture.

Ellis, G. D., Freeman, P. A., Jamal, T., \& Jiang, J. (2019). A theory of structured experience. Annals of Leisure Research, 22(1), 97-118. https://doi.org/10.1080/11745398.2017.1312468

Ellis, G. D., Freeman, P., Jiang, J., \& Lacanienta, A. (2019). Measurement of deep structured experiences as a binary phenomenon. Annals of Leisure Research. 22(1), 119-126. https://doi.org/10.1080/11745398.2018.1429285

Ellis, G., Lacanienta, A., \& Freeman, P. (2018). Reducing attrition from youth programs through structuring deep, valued, and impactful experiences for youth. In P. Witt and L. Caldwell (Eds.). Youth development: Principles and practices in out-of-school time settings. ( $2^{\text {nd }}$ ed., pp. 351387). Sagamore-Venture.

Ellis, G. D., Taggart, A. S., Martz, J., Lepley, T., \& Jamal, T. (2016). Monitoring structured experiences during youth programs: Development of brief measures of perceived value and engagement. Journal of Youth Development, 11(3), 159-174. https://doi.org/10.5195/jyd.2016.469

Fiocco, A. J., \& Mallya, S. (2015). The importance of cultivating mindfulness for cognitive and emotional well-being in late life. Journal of Evidence-Based Complementary and Alternative Medicine, 20, 35-40. https://doi.org/10.1177/2156587214553940

Gallant, S. N. (2016). Mindfulness meditation practice and executive functioning: breaking down the benefit. Consciousness and Cognition, 40, 116-130. https://doi.org/10.1016/j.concog.2016.01.005

Hassed, C., \& Chambers, R. (2014). Mindful Learning. Shambhala Publications. 
Journal of Youth Development | http://jyd.pitt.edu/ | Vol. 15 Issue 5 DOI 10.5195/jyd.2020.797

Mindfulness and Absorption

Hyland, T. (2011). Mindfulness and learning: Celebrating the affective dimension of education. Springer. Kabat-Zinn, J. (2003). Mindfulness-based interventions in context: past, present, and future. Clinical Psychology: Science and Practice, 10, 144-156. https://doi.org/10.1093/clipsy.bpg016

Lacanienta, A., Ellis, G., Taggart, A., Wilder, J., \& Carroll, M. (2018). Does theming camp experiences lead to greater quality, satisfaction, and promotion? Journal of Youth Development, 13(1-2), 216239. https://doi.org/10.5195/jyd.2018.535

Langer, E. J. (2000). Mindful learning. Current Directions in Psychological Science, 9(6), 220-223. https://doi.org/10.1111/1467-8721.00099

Langer, E. J. (2014a). Mindfulness (25 ${ }^{\text {th }}$ Anniversary ed.). De Capo Press.

Langer, E. J. (2014b). Mindfulness forward and back. In A. Le, C. T. Ngnoumen, \& E. J. Langer (Eds.), The Wiley Blackwell handbook of mindfulness, (pp. 7-20). John Wiley \& Sons. https://doi.org/10.1002/9781118294895.ch1

Langer, E. J. (2016). The power of mindful learning. ( ${ }^{\text {nd }}$ ed.). De Capo Press.

Larson, R., \& Walker, K. (2018). Process of positive development: Classic theories. In Witt, P. \& Caldwell, L. (Ed.), Youth development: Principles and practices in out-of-school time settings (pp. 155171). Sagamore Venture.

Le, A., Ngnoumen, C., \& Langer, E. (2014). (Eds). The Wiley Blackwell handbook of mindfulness. John Wiley \& Sons.

Oliver, R. L. (2010). Satisfaction: A behavioral perspective on the consumer. Routledge.

Pine, B. J., \& Gilmore, J. H. (2011). The experience economy. Harvard Business Press.

Ramsburg, J. T., \& Youmans, R. J. (2014). Meditation in the higher-education classroom: Meditation training improves student knowledge retention during lectures. Mindfulness, 5(4), 431-441. https://doi.org/10.1007/s12671-013-0199-5

Reichheld, F. F. (2003). The one number you need to grow. Harvard Business Review, 81(12), 46-55. https://hbr.org/2003/12/the-one-number-you-need-to-grow

Ricarte, J. J., Ros, L., Latorre, J. M., \& Beltrán, M. T. (2015). Mindfulness-based intervention in a rural primary school: Effects on attention, concentration and mood. International Journal of Cognitive Therapy, 8(3), 1-13. https://doi.org/10.1521/ijct $2015 \quad 803$

Witt, P. and Caldwell, L. (Eds) (2018). Youth development principles and practices in out-of-school time settings. Sagamore-Venture. 